\title{
Effects of 405-nm LED Treatment on the Resistance of Listeria monocytogenes to Subsequent Environmental Stresses
}

\author{
Shenmin Kang ${ }^{1}$, Yujie Meng ${ }^{1}$, Xiaomeng Cheng ${ }^{1}$, Junhong $T u^{1}$, Du Guo ${ }^{1}$, Yunfeng $X u^{2}$, \\ Sen Liang ${ }^{3}$, Xiaodong Xia ${ }^{1}$ and Chao Shit ${ }^{*}$ \\ ${ }^{1}$ College of Food Science and Engineering, Northwest A\&F University, Yangling, China, ${ }^{2}$ College of Food \\ and Bioengineering, Henan University of Science and Technology, Luoyang, China, ${ }^{3}$ Beijing Advanced Innovation Center \\ for Food Nutrition and Human Health, Beijing Technology and Business University, Beijing, China
}

OPEN ACCESS

Edited by: Lin Lin,

Jiangsu University, China

Reviewed by: Krzysztof Skowron, Nicolaus Copernicus University in Toruń, Poland

Anca loana Nicolau, Dunarea de Jos University, Romania

*Correspondence: Chao Shi meilixinong@nwsuaf.edu.cn

Specialty section: This article was submitted to

Food Microbiology,

a section of the journal

Frontiers in Microbiology

Received: 12 June 2019 Accepted: 05 August 2019 Published: 16 August 2019

Citation: Kang S, Meng Y, Cheng X, Tu J, Guo D, Xu Y, Liang S, Xia X and Shi C (2019) Effects of 405-nm LED Treatment on the Resistance of Listeria monocytogenes to Subsequent Environmental Stresses. Front. Microbiol. 10:1907. doi: 10.3389/fmicb.2019.01907
Listeria monocytogenes can persist under a wide range of stress conditions, contributing to its ubiquitous distribution and unique pathogenic traits. Light from lightemitting diodes (LEDs) has recently been shown to inactivate various pathogens. Thus, the aim of the present study was to evaluate the effects of light treatment using a 405$\mathrm{nm}$ LED on the subsequent resistance of $L$. monocytogenes to environmental stresses, including oxidative stress, ultraviolet (UV) irradiation, low temperature, osmotic pressure, simulated gastric fluid (SGF), and bile salts. Following 405-nm LED illumination at $4^{\circ} \mathrm{C}$ for 150 min, the survival of $L$. monocytogenes was examined after exposure to oxidative stress $\left(0.04 \% \mathrm{H}_{2} \mathrm{O}_{2}\right)$, UV irradiation ( $\left.253.7 \mathrm{~nm}\right)$, low temperature $\left(4^{\circ} \mathrm{C}\right)$, osmotic pressure $(10,15$, or $20 \% \mathrm{NaCl})$, SGF (pH 2.5), or bile salts (2\%). The mechanisms responsible for changes in stress tolerance were identified by assessing the transcriptional responses and membrane integrity of $L$. monocytogenes. The 405-nm LED treatment reduced the resistance of $L$. monocytogenes to all the stresses tested. Reverse transcription quantitative real-time polymerase chain reaction analysis indicated that the transcription of multiple genes associated with stress resistance, including betL, gbuA, oppA, fri, bsh, and $\operatorname{arcA}$, was reduced by 405-nm LED. Confocal laser scanning microscopy revealed that $405-n m$ LED treatment disrupted the integrity of the $L$. monocytogenes cell membrane compared with untreated bacteria. Therefore, 405-nm LED illumination appears to reduce the resistance of $L$. monocytogenes to various stress conditions. These findings suggest that 405-nm LED treatment could be used to effectively prevent and/or control with L. monocytogenes contamination along the entire food-processing chain, from production to consumption.

Keywords: L. monocytogenes, LED, environmental stress resistance, cell membrane integrity, resistance gene

\section{INTRODUCTION}

Listeria monocytogenes is a foodborne, facultative, intracellular human pathogen that is highly resistant to various stress conditions (Bucur et al., 2018). It crosses both the blood-brain and intestinal barriers, causing life-threatening infections. L. monocytogenes is the most common cause of the serious foodborne disease listeriosis, a sporadic bacterial infection that affects many animal 
species, including humans (Scallan et al., 2011). Older adults, pregnant women, newborns, and immunodeficient individuals are especially susceptible to listeriosis (Lecuit, 2007). Patients infected with Listeria often suffer meningitis, sepsis, and other central nervous system infections, while listeriosis can also cause spontaneous abortion in pregnant women (Rocourt, 2019). In 2016, 270 deaths attributable to listeriosis were reported across 19 member states of the European Union (EU). In the same year, the overall EU notification rate for listeriosis was 0.46 cases per 100,000 population, with a case-fatality rate of $17.7 \%$ (Boelaert et al., 2016). Many studies have shown that rivers, sewage, and natural soils are reservoirs of L. monocytogenes (Schaffter and Parriaux, 2002; Watkins and Sleath, 2010). However, processed foods are common sources of infection, including raw milk products, cold meats, pâtés, and ready-to-eat chilled products (Lecuit, 2007; Allerberger and Wagner, 2010), although unprocessed foods, such as fruit and vegetables, have also been identified as vectors (Garner and Kathariou, 2016).

Listeria monocytogenes can tolerate oxidative environments and was reported to survive for more than $15 \mathrm{~min}$ after exposure to the oxidative agent cumene hydroperoxide (13.8 $\mathrm{mM})$ (Ferreira et al., 2001). Studies have shown that the persistence of L. monocytogenes under oxidative conditions is related to stress regulators encoded by $\operatorname{sig} B$ and $\operatorname{per} R$, antioxidant genes sod, kat, and fri, and the DNA repair gene recA (Fisher et al., 2000; Bredèche et al., 2001; Rea et al., 2005; Fiorini et al., 2008; Van der Veen and Abee, 2010). Refrigeration is commonly used to extend the shelf-life of food products. Various studies have demonstrated that L. monocytogenes can survive and grow at refrigeration temperatures $\left(2-4^{\circ} \mathrm{C}\right)$; although, at these temperatures, its doubling time can be $50 \mathrm{~h}$ or more (Feng et al., 2010). Bayles et al. (1996) showed that L. monocytogenes contains 12 cold-shock proteins, that allow it to survive and grow at low temperatures. L. monocytogenes strains can also adapt to highly osmotic environments, surviving for 150 days in pure salt at ambient temperature (Besse et al., 2010) and thriving at $\mathrm{NaCl}$ concentrations of up to $14 \%(\mathrm{w} / \mathrm{v})$ (Farber et al., 2010). The mechanism underlying the response of L. monocytogenes to high osmotic pressure depends on the synthesis or uptake of compatible solutes, including glycine betaine, proline, and carnitine, to balance its internal and external environments (Gardan et al., 2003; Sleator et al., 2003). L. monocytogenes is also resistant to ultraviolet (UV) irradiation, acid, and bile salts (Gabriel and Nakano, 2009; Feng et al., 2010; Chorianopoulos et al., 2011). The multifaceted environmental tolerance of L. monocytogenes increases its ability to survive the food processing chain, increasing the risk of human infection and the difficulty of eliminating it.

Light emitting diodes (LEDs) are semiconductor devices that emit visible light. The many advantages of LEDs include low energy consumption, longevity, and non-polluting action (Murdoch et al., 2010). In recent years, researchers have investigated the potential utility of specific-wavelength LEDs to eliminate foodborne pathogens. Studies have shown that illumination with a 405-nm LED has strong bacteriostatic effects on Gram-positive bacteria, including Bacillus cereus and Staphylococcus aureus (Kim et al., 2015), and an antibacterial effect on Escherichia coli O157:H7 on the surface of freshcut mango (Kim et al., 2016). Endarko et al. (2012) showed that 405-nm LED treatment exerted a strong germicidal effect on L. monocytogenes. Several studies have proposed different mechanisms for the killing effects of LED treatment on bacterial cells. One group suggested that after bacteria are exposed to blue-violet light in the presence of oxygen, an endogenous porphyrin compound can absorb light and then excite electrons, producing reactive oxygen species (ROS) (Dai et al., 2012). ROS such as superoxide ions may cause cytotoxicity by reacting with intracellular components including DNA and proteins, resulting in bacterial death (Luksiene, 2003). Other studies have shown that the antibacterial effect of 405-nm LED treatment may be partly attributed to the physical damage caused to the bacterial cell membrane (Kim et al., 2015). However, few studies have examined the effects of 405-nm LED treatment on the resistance of L. monocytogenes to environmental stresses, or what the underlying mechanisms may be.

The aim of the current study was to investigate the effects of 405-nm LED treatment on the resistance of L. monocytogenes to environmental stresses. Differences in the resistance of illuminated versus unilluminated bacteria to oxidative stress, UV irradiation, osmotic pressure, low temperature, simulated gastric fluid (SGF), and bile salts were detected. The effects of LED illumination on the integrity of the L. monocytogenes cell membrane was also examined using confocal laser scanning microscopy (CLSM). Finally, reverse transcription quantitative real-time polymerase chain reaction (RT-qPCR) was used to investigate the effects of $405-\mathrm{nm}$ LED treatment on the transcription of resistance-related genes in L. monocytogenes.

\section{MATERIALS AND METHODS}

\section{Bacterial Strains and Culture Conditions}

Listeria monocytogenes strain ATCC 19115 was purchased from the American Type Culture Collection (Manassas, VA, United States) and it was used for further experiments because it is commonly used in studies about environmental resistance of L. monocytogenes and it contains phenotypic and genotypic characteristics tested in the following experiments. The strain was stored at $-80^{\circ} \mathrm{C}$. Bacteria were subcultured on trypticase soy agar (TSA; Land Bridge, Beijing, China) for $30 \mathrm{~h}$ at $37^{\circ} \mathrm{C}$. A single colony was then inoculated into $30 \mathrm{~mL}$ of sterile tryptic soy broth (TSB; Land Bridge) and incubated with shaking at $130 \mathrm{rpm}$ for $18-24 \mathrm{~h}$ at $37^{\circ} \mathrm{C}$. This working culture was then centrifuged at $8000 \times g$ for $10 \mathrm{~min}$ at $4^{\circ} \mathrm{C}$ and the cell pellet was washed twice with phosphate-buffered saline (PBS; pH 7.4). The pellet was then resuspended in PBS to produce a concentrated cell culture (approximately $10^{9}$ colony-forming units $(\mathrm{CFU}) / \mathrm{mL}$ ).

\section{LED Illumination}

The 405-nm LED was purchased from Shenzhen Boya Technology Co., Ltd. (Shenzhen, China). The LED illumination system was designed as reported by Ghate et al. (2013). Briefly, the LED was surrounded by acrylonitrile butadiene styrene housing and a cooling fan and a heat sink were attached to cool 
the apparatus during the illumination process. To protect the LED from excessive current, $5 \Omega$ of resistance was linked into the circuit. The distance between the LED source and the bacterial suspension, contained in a sterile Petri dish $(90 \times 15 \mathrm{~mm})$, was $4.5 \mathrm{~cm}$ to ensure that no visible color fading was generated on the suspension during LED illumination. A digital thermometer (DTM-280; Shanghai Shuangqiao Instrument Co., Ltd., Shanghai, China) was used to monitor fluctuations in the temperature of the bacterial suspension during LED illumination over $4 \mathrm{~h}$. To compensate for the temperature increase during LED illumination, the unilluminated L. monocytogenes cultures were placed in an incubator at $5.4^{\circ} \mathrm{C}$ in the dark, compensating for the increase in temperature measured in the illuminated culture (measured as $1.4^{\circ} \mathrm{C}$ ). The dose of LED illumination received by each bacterial sample was calculated using the formula: $\mathrm{E}=\mathrm{Pt}$, where $\mathrm{E}$ is dose (energy density) in $\mathrm{J} / \mathrm{cm}^{2}, \mathrm{P}$ is the irradiance (power density) in $\mathrm{mW} / \mathrm{cm}^{2}$, and $\mathrm{t}$ is the time in seconds (Maclean et al., 2009).

\section{Bacterial Inoculation and LED Illumination}

Aliquots $(2 \mathrm{~mL}$ ) of bacterial suspension (prepared as described in section "Bacterial Strains and Culture Conditions") were diluted in $18 \mathrm{~mL}$ of PBS to produce the test cultures. Test cultures were aspirated into sterile Petri dishes $(90 \times 15 \mathrm{~mm})$ and illuminated using $405-\mathrm{nm} \operatorname{LED}\left(18.9 \pm 1.4 \mathrm{~mW} / \mathrm{cm}^{2}\right)$ for $240 \mathrm{~min}$ at $4^{\circ} \mathrm{C}$. Unilluminated samples were placed in an incubator at $5.4^{\circ} \mathrm{C}$. At time points $0,30,90,150,180$, and $240 \mathrm{~min}$, aliquots of both illuminated and unilluminated samples were collected diluted in sterile PBS, and plated onto TSA plates. The plates were incubated for $24-48 \mathrm{~h}$ at $37^{\circ} \mathrm{C}$ for colony enumeration.

\section{Determination of Resistance to Environmental Stress Conditions}

Listeria monocytogenes ATCC 19115 treated with 405-nm LED for $150 \mathrm{~min}$ at $4^{\circ} \mathrm{C}$ was used to study resistance to environmental stresses. Unilluminated samples were incubated for $150 \mathrm{~min}$ at $5.4^{\circ} \mathrm{C}$. Following all treatments, samples were serially diluted in PBS and then plated onto appropriate agar plates for colony enumeration. Final bacterial counts were calculated as $\log \mathrm{CFU} / \mathrm{mL}$.

\section{Resistance of L. monocytogenes to Oxidative Stress}

To evaluate the survival of $L$. monocytogenes in the presence of $0.04 \%(\mathrm{v} / \mathrm{v}) \mathrm{H}_{2} \mathrm{O}_{2}$, unilluminated and LED-illuminated samples were transferred to separate sterile tubes. An equal volume of PBS containing $0.08 \%(\mathrm{v} / \mathrm{v}) \mathrm{H}_{2} \mathrm{O}_{2}$ was added to each tube and gently mixed before the cultures were incubated at $25^{\circ} \mathrm{C}$. Samples were collected from each tube at $5 \mathrm{~min}$ intervals for $20 \mathrm{~min}$ and plated on TSA.

\section{UV Resistance of L. monocytogenes}

To examine the survival of L. monocytogenes following exposure to UV irradiation, unilluminated and LED-illuminated samples were aspirated into sterile Petri dishes $(90 \times 15 \mathrm{~mm})$ and exposed to UV irradiation. An 8-W UV light (UV-C; $253.7 \mathrm{~nm}$ ) was purchased from Haining Haishi Lighting Co., Ltd. (Haining,
China). The distance between the UV source and the bacterial suspensions was $55 \mathrm{~cm}$. After UV irradiation for 0, 20, $40,60,120,180$, or $240 \mathrm{~s}$, cultures were serially diluted and plated on TSA.

\section{Cold Resistance of $L$. monocytogenes}

The cold resistance of $L$. monocytogenes was determined by incubating unilluminated and LED-illuminated L. monocytogenes at $4^{\circ} \mathrm{C}$. Cultures were sampled at $0,4,24,48$, and $96 \mathrm{~h}$ post-coldexposure and plated on TSA.

Resistance of $L$. monocytogenes to Osmotic Pressure To evaluate the effects of osmotic pressure on L. monocytogenes survival, $\mathrm{NaCl}$ was added to the unilluminated and LEDilluminated samples to a final concentration of 10,15 , or $20 \%$ $(\mathrm{w} / \mathrm{v})$. Cultures were then incubated at $25^{\circ} \mathrm{C}$ and samples were collected at $0,20,30,40,60$, or $120 \mathrm{~min}$ and plated on TSA for colony enumeration.

\section{SGF Resistance of L. monocytogenes}

Simulated gastric fluid ( $\mathrm{pH} 2.5)$ was prepared according to Yang et al. (2015) and consisted of $8.3 \mathrm{~g}$ proteose peptone (Solarbio, Beijing, China), 0.6 g $\mathrm{KH}_{2} \mathrm{PO}_{4}, 2.05 \mathrm{~g} \mathrm{NaCl}, 0.37 \mathrm{~g}$ $\mathrm{KCl}, 0.11 \mathrm{~g} \mathrm{CaCl}_{2}, 0.05 \mathrm{~g}$ oxgall (Sigma Aldrich, St. Louis, MO, United States), $1 \mathrm{~g}$ lysozyme (Solarbio), and $13.3 \mathrm{mg}$ pepsin (1:3000; Solarbio). All of the compounds were dissolved in deionized water and autoclaved together, except for the oxgall, lysozyme, and pepsin, which were sterilized by filtration $(0.25 \mu \mathrm{m}$ pore size). The solution was adjusted to $\mathrm{pH} 2.5$ with $5.0 \mathrm{~N} \mathrm{HCl}$.

The acid resistance of the $L$. monocytogenes strains was determined according to Yang et al. (2015). SGF was inoculated with unilluminated or LED-illuminated samples at a ratio of 9:1 and incubated with shaking $(130 \mathrm{rpm})$ at $37^{\circ} \mathrm{C}$. Aliquots were collected from each sample at $0,2,5,10,20$, or $30 \mathrm{~min}$ post-inoculation and plated on TSA.

\section{Resistance of $L$. monocytogenes to Bile Salts}

To evaluate the survival of $L$. monocytogenes in the presence of $2 \%(\mathrm{w} / \mathrm{v})$ bile salts, bile salt solution (Sigma Aldrich) was added to the unilluminated and LED-illuminated samples to a final concentration of $2 \%(\mathrm{w} / \mathrm{v})$, placed on a shaker $(130 \mathrm{rpm})$, and incubated at $37^{\circ} \mathrm{C}$. At $0,30,60,120,180$, or $240 \mathrm{~min}$, the cultures were serially diluted and plated on TSA. Plates were incubated at $37^{\circ} \mathrm{C}$ for $24-48 \mathrm{~h}$ for colony enumeration.

\section{Effect of 405-nm LED on L. monocytogenes Treatment Cell Membrane Integrity}

Listeria monocytogenes ATCC 19115 was illuminated with 405-nm LED at $4^{\circ} \mathrm{C}$ for 90 or $150 \mathrm{~min}$. Unilluminated L. monocytogenes was incubated at $5.4^{\circ} \mathrm{C}$ for 90 or $150 \mathrm{~min}$. Both unilluminated and LED-illuminated samples were then centrifuged at $10,000 \times g$ for $2 \mathrm{~min}$ at $4^{\circ} \mathrm{C}$ to obtain the cell pellets, which were resuspended in $0.85 \%$ (w/v) $\mathrm{NaCl}$. The reagents SYTO 9 and propidium iodide (PI) were prepared according to the manufacturer's instructions and mixed in equal proportions. A $3 \mu \mathrm{L}$ aliquot of this mixture was then added to 
a $1-\mathrm{mL}$ aliquot of each cell suspension in $0.85 \%(\mathrm{w} / \mathrm{v}) \mathrm{NaCl}$ and the cells were incubated for $10 \mathrm{~min}$ in the dark. The stained cells were examined by CLSM (A1 confocal laser microscope; Nikon, Tokyo, Japan) under $400 \times$ magnification.

\section{Effect of 405-nm LED Treatment on Gene Transcription in $L$. monocytogenes}

Listeria monocytogenes ATCC 19115 was illuminated using the $405-\mathrm{nm}$ LED at $4^{\circ} \mathrm{C}$ for $150 \mathrm{~min}$. Unilluminated L. monocytogenes was incubated at $5.4^{\circ} \mathrm{C}$ for $150 \mathrm{~min}$. Cultures were then centrifuged $\left(5000 \times g, 5 \mathrm{~min}, 4^{\circ} \mathrm{C}\right)$ and resuspended in PBS. Total RNA was extracted using a RNAprep Pure Kit (Tiangen, Beijing, China) according to the manufacturer's instructions. RNA concentrations were measured using a nucleic acid and protein spectrophotometer (Nano-200; Aosheng Instrument Co., Ltd., Hangzhou, China). The isolated RNA samples were then reverse transcribed into cDNA, and RT-qPCR was performed as per the method of Shi et al. (2018). All samples were analyzed in triplicate, and gene expression was normalized against that of the endogenous control (16S rRNA gene). The primers used in this study are listed in Table 1. The samples were analyzed using the IQ5 system (Bio-Rad Laboratories, Hercules, CA, United States) and the expression of the target genes and the 16S rRNA gene was determined as described above. The relative expression levels of the target genes was determined using the $2^{-\Delta \Delta C t}$ method.

\section{Statistical Analysis}

All experiments were performed in triplicate. The data are expressed as means \pm standard deviations and were statistically analyzed using SPSS version 19.0 (SPSS Inc., Chicago, IL, United States). Significant differences were determined using the LSD method. The differences between groups were considered significant at $P<0.05$ and extremely significant at $P<0.01$.

TABLE 1 | Primers used in this study for RT-qPCR analyses.

\begin{tabular}{|c|c|}
\hline Gene & Sequence of primers $\left(5^{\prime}-3^{\prime}\right)$ \\
\hline 16S rRNA & $\begin{array}{l}\text { F: GATGCATAGCCGACCTGAGA } \\
\text { R: TGCTCCGTCAGACTITCGTC }\end{array}$ \\
\hline $\operatorname{sig} B$ & $\begin{array}{l}\text { F: CATTGCTGATTTCATCGGTGT } \\
\text { R: CCACCAACAACATCTAATAAGG }\end{array}$ \\
\hline betL & $\begin{array}{l}\text { F: TGGGCTTGGTGGCTTCT } \\
\text { R: TCGCTAAACTTGAAAGACCAG }\end{array}$ \\
\hline gbuA & $\begin{array}{l}\text { F: GTCCATGCAGCGGAAGTTTC } \\
\text { R: CATCTTCGGTTACAGCAATCG }\end{array}$ \\
\hline $\operatorname{arc} A$ & $\begin{array}{l}\text { F: TCTTGTCGGTGTATCTGAGCG } \\
\text { R: CCATGGTGAAAACCGTATCC }\end{array}$ \\
\hline bsh & $\begin{array}{l}\text { F: TATGATAATCCTGTTGGCGTGTT } \\
\text { R: GAAGATAAATCGCCAGGTAAGC }\end{array}$ \\
\hline oppA & $\begin{array}{l}\text { F: CGGTGGAGATATCGTAGCTG } \\
\text { R: AACTCGAAAGGTCCATTGAA }\end{array}$ \\
\hline fri & $\begin{array}{l}\text { F: CACCAAGTAGCGAACCTAAACG } \\
\text { R: TAAGCGTTCTGCTACTTCGTCC }\end{array}$ \\
\hline
\end{tabular}

\section{RESULTS}

\section{Temperature of $L$. monocytogenes Suspension During LED Illumination}

The temperature of the $L$. monocytogenes suspension was measured every $1 \mathrm{~min}$ for $240 \mathrm{~min}$ during LED illumination. After 70 min of measurement, regular fluctuations in temperature were recorded. Overall, the temperature rose by an average of $1.4^{\circ} \mathrm{C}$ when the $L$. monocytogenes suspension at the set temperature of $4^{\circ} \mathrm{C}$ was illuminated using the 405-nm LED. The regular fluctuations continued until the end of measurement period (Supplementary Figure S1). Therefore, when the test cells were illuminated for $150 \mathrm{~min}$ (total dose of $170 \mathrm{~J} / \mathrm{cm}^{2}$ ) at $4^{\circ} \mathrm{C}$, the unilluminated L. monocytogenes cells were placed in an incubator at $5.4^{\circ} \mathrm{C}$ to compensate for the increase in temperature in the illuminated suspension.

\section{Survival of $L$. monocytogenes Following 405-nm LED Treatment}

Following illumination using the 405-nm LED $\left(18.9 \pm 1.4 \mathrm{~mW} / \mathrm{cm}^{2}\right)$ for 90,150 , or $180 \mathrm{~min}$, the total doses of LED illumination received by the bacterial suspensions were 102,170 , and $204 \mathrm{~J} / \mathrm{cm}^{2}$, respectively.

Changes in the survival of L. monocytogenes illuminated with the 405-nm LED are shown in Figure 1. The initial concentration of L. monocytogenes was $7.8 \log \mathrm{CFU} / \mathrm{mL}$. Following illumination at $4^{\circ} \mathrm{C}$ for 90,150 , or $180 \mathrm{~min}$, the concentration of $L$. monocytogenes cells was reduced by $0.5,2.9$, and $3.6 \log \mathrm{CFU} / \mathrm{mL}$, respectively, whereas the populations in the unilluminated samples fluctuated around $7.8 \log \mathrm{CFU} / \mathrm{mL}$. The bacterial numbers in the LED-illuminated and unilluminated samples differed significantly $(P<0.01)$ after LED illumination for $150 \mathrm{~min}$. Therefore, illumination for $150 \mathrm{~min}$ (a total dose of $170 \mathrm{~J} / \mathrm{cm}^{2}$ ) was chosen as the sample treatment to study the effects of LED illumination on the resistance of L. monocytogenes to different environmental stresses.

\section{Environmental Stress Resistance of L. monocytogenes}

Resistance of $L$. monocytogenes to Oxidative Stress

The effects of 405-nm LED treatment on the oxidative stress resistance of L. monocytogenes are shown in Figure 2A. Bacterial concentrations in the unilluminated samples remained at about $4.8 \log \mathrm{CFU} / \mathrm{mL}$ after a 20 -min exposure to $0.04 \% \mathrm{H}_{2} \mathrm{O}_{2}$. In contrast, L. monocytogenes concentrations in the illuminated samples decreased rapidly in the first $5 \mathrm{~min}$, resulting in a significant differences $(P<0.01)$ in concentration compared with the unilluminated samples. After this time point, bacterial concentrations remained constant $(1.8 \log \mathrm{CFU} / \mathrm{mL})$ until the end of the experimental period.

\section{UV Resistance of $L$. monocytogenes}

Figure 2B shows the effect of 405-nm LED treatment on the resistance of $L$. monocytogenes to $U V$ irradiation. The bacterial population decreased significantly $(P<0.01)$ after UV irradiation. Following UV irradiation for 40, 60, or $120 \mathrm{~s}$, the 


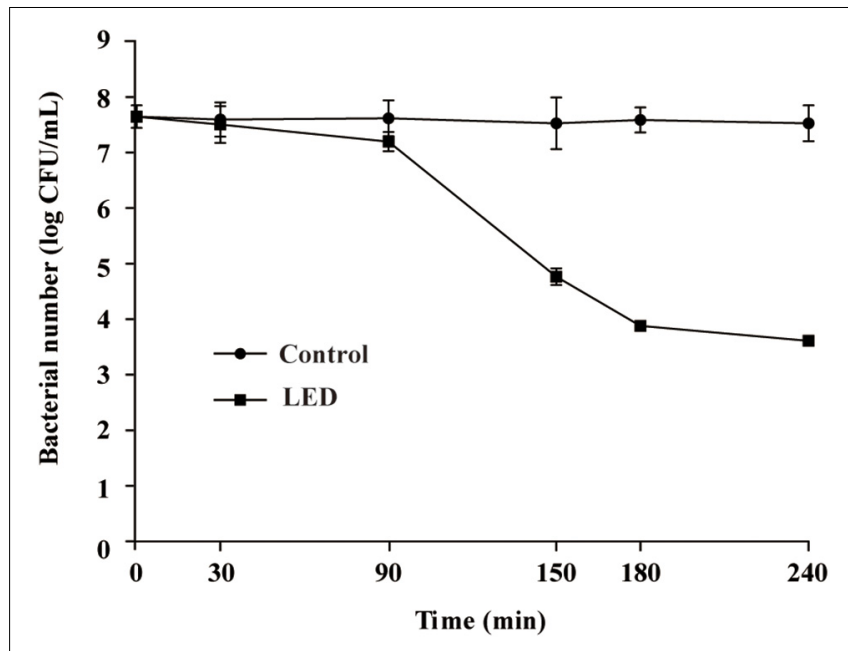

FIGURE 1 | Effect of 405-nm LED illumination on the survival of L. monocytogenes suspensions at $4^{\circ} \mathrm{C}$.

numbers of bacteria in the unilluminated samples decreased by about $0.4,0.7$, and $2.0 \log \mathrm{CFU} / \mathrm{mL}$, respectively, and decreased to below the detection limit after $180 \mathrm{~s}$. Decreases in bacterial numbers in the illuminated cultures following $20 \mathrm{~s}$ of UV irradiation were significantly $(P<0.01)$ greater than those observed in the unilluminated cultures, with population numbers dropping below the detection limit within $40 \mathrm{~s}$.

\section{Cold Resistance of L. monocytogenes}

The initial concentrations of illuminated and unilluminated bacteria were about $4.6 \log \mathrm{CFU} / \mathrm{mL}$ (Figure 2C). In the unilluminated samples refrigerated at $4^{\circ} \mathrm{C}$ for $24 \mathrm{~h}$, the L. monocytogenes counts increased by about $0.5 \log \mathrm{CFU} / \mathrm{mL}$, but decreased to $4.4 \log \mathrm{CFU} / \mathrm{mL}$ after $96 \mathrm{~h}$. When illuminated with LED, the L. monocytogenes counts decreased slightly in the first $24 \mathrm{~h}$, falling to $4.2 \log \mathrm{CFU} / \mathrm{mL}$ after $96 \mathrm{~h}$. There was a significant difference $(P<0.01)$ between the illuminated and unilluminated cultures in the first $24 \mathrm{~h}$, but no significant difference was noted between the culture types after $24 \mathrm{~h}(P>0.05)$.

\section{Resistance of L. monocytogenes to Osmotic Pressure}

The survival of LED-illuminated L. monocytogenes cultures exposed to 10,15 , and $20 \%(\mathrm{w} / \mathrm{v}) \mathrm{NaCl}$ is shown in Figures 3AC, respectively. After the $\mathrm{NaCl}$ solutions were inoculated with the samples, the concentration of L. monocytogenes was $3.6 \log \mathrm{CFU} / \mathrm{mL}$ in each sample. L. monocytogenes concentrations in the unilluminated samples remained at around $3.6 \log \mathrm{CFU} / \mathrm{mL}$ regardless of the $\mathrm{NaCl}$ concentration. In comparison, illuminated bacterial sample concentrations significantly decreased following exposure to $10 \% \mathrm{NaCl}$ $(P<0.01)$, decreasing to $2.3 \log \mathrm{CFU} / \mathrm{mL}$ after $20 \mathrm{~min}$ and $1.1 \log \mathrm{CFU} / \mathrm{mL}$ after 20-120-min exposure times (Figure 3A). The concentrations of LED-illuminated L. monocytogenes cultures incubated in 15 and $20 \% \mathrm{NaCl}$ for $30 \mathrm{~min}$ decreased to about 1.1 and $0.9 \log \mathrm{CFU} / \mathrm{mL}$, respectively, and dropped below the detection limit after $60 \mathrm{~min}$ (Figures 3B,C).
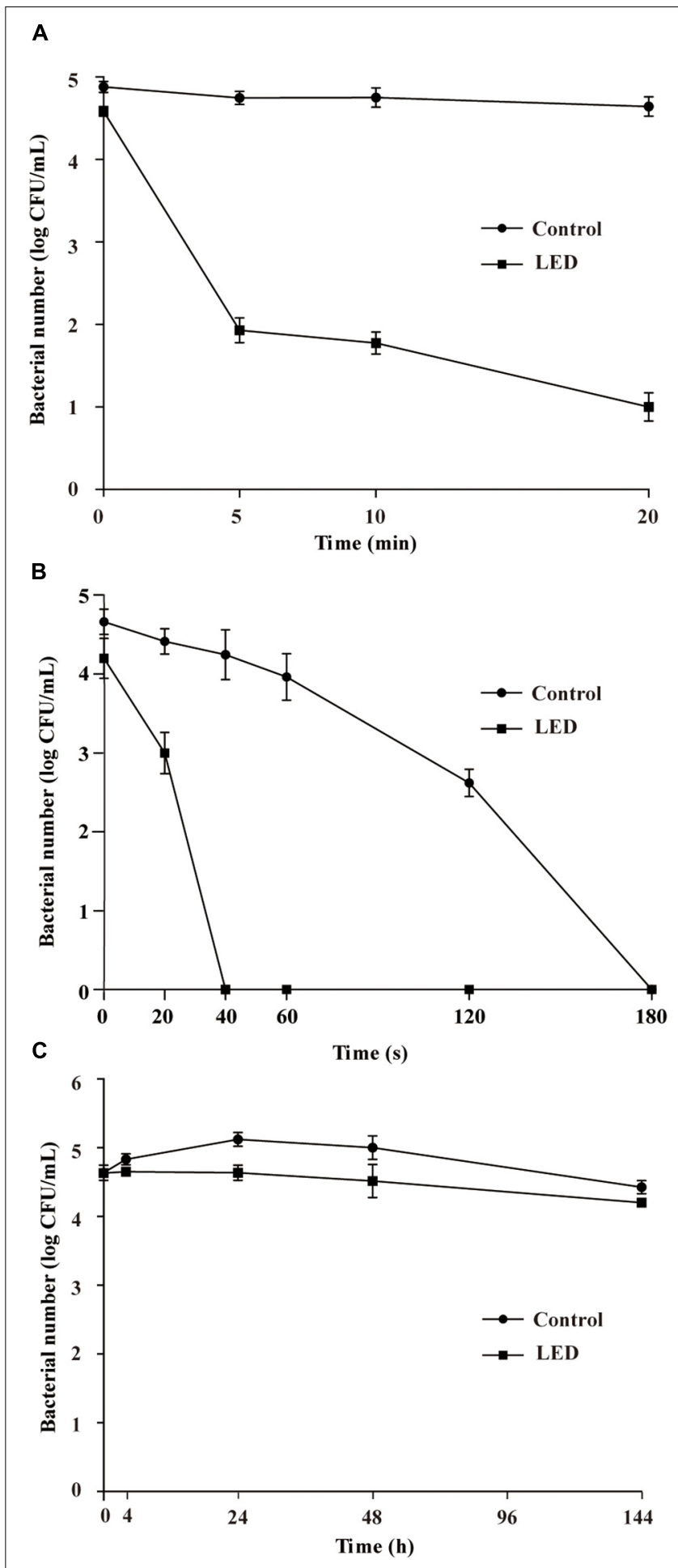

FIGURE 2 | Survival of LED-illuminated and unilluminated L. monocytogenes cultures in $0.04 \% \mathrm{H}_{2} \mathrm{O}_{2}$ (A), under UV irradiation (B), and at $4^{\circ} \mathrm{C}$ (C).

\section{Resistance of $L$. monocytogenes to SGF}

Figure 4A shows the effects of 405-nm LED treatment on the resistance of L. monocytogenes to SGF. After exposure to SGF for 

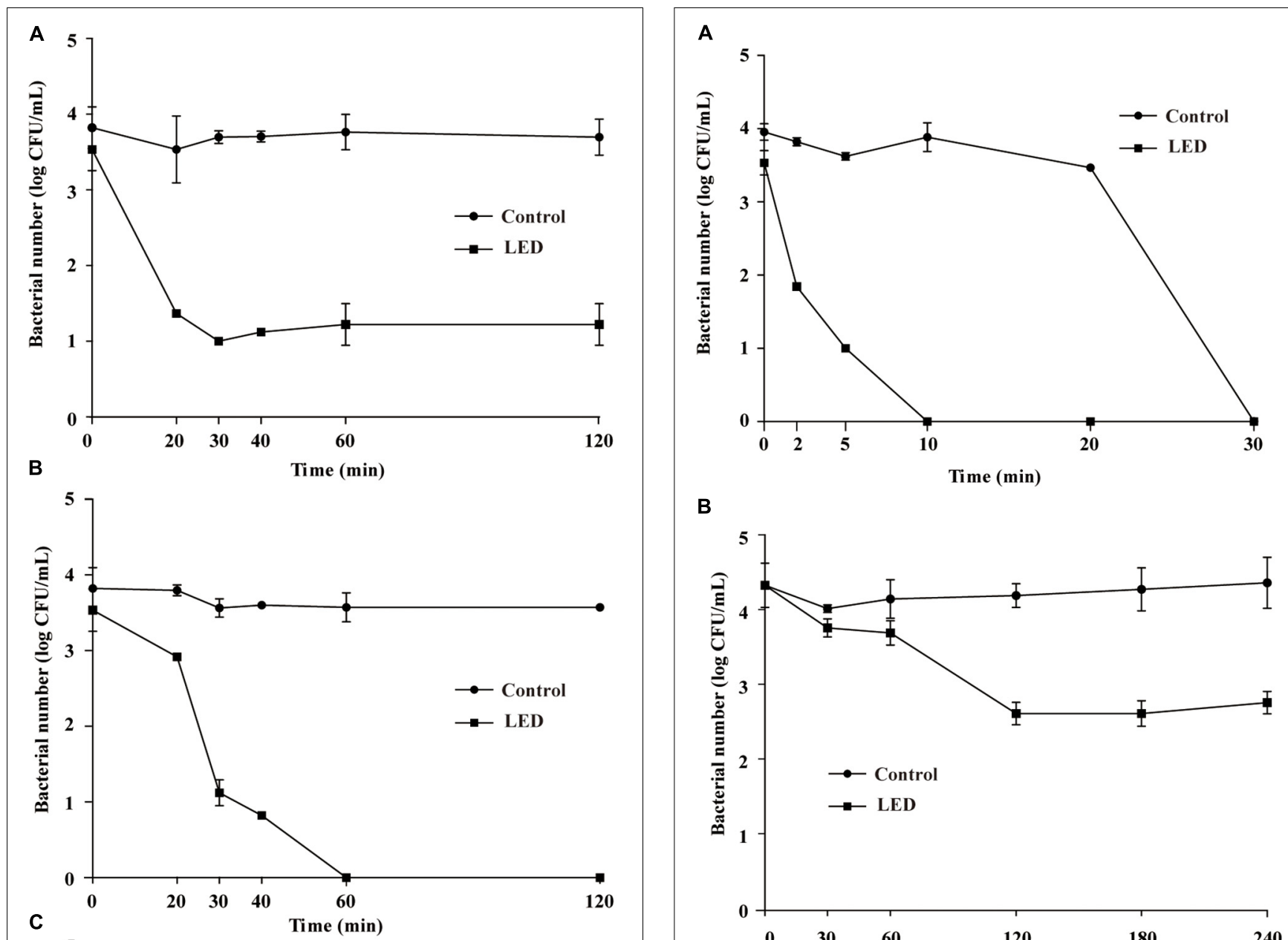

B
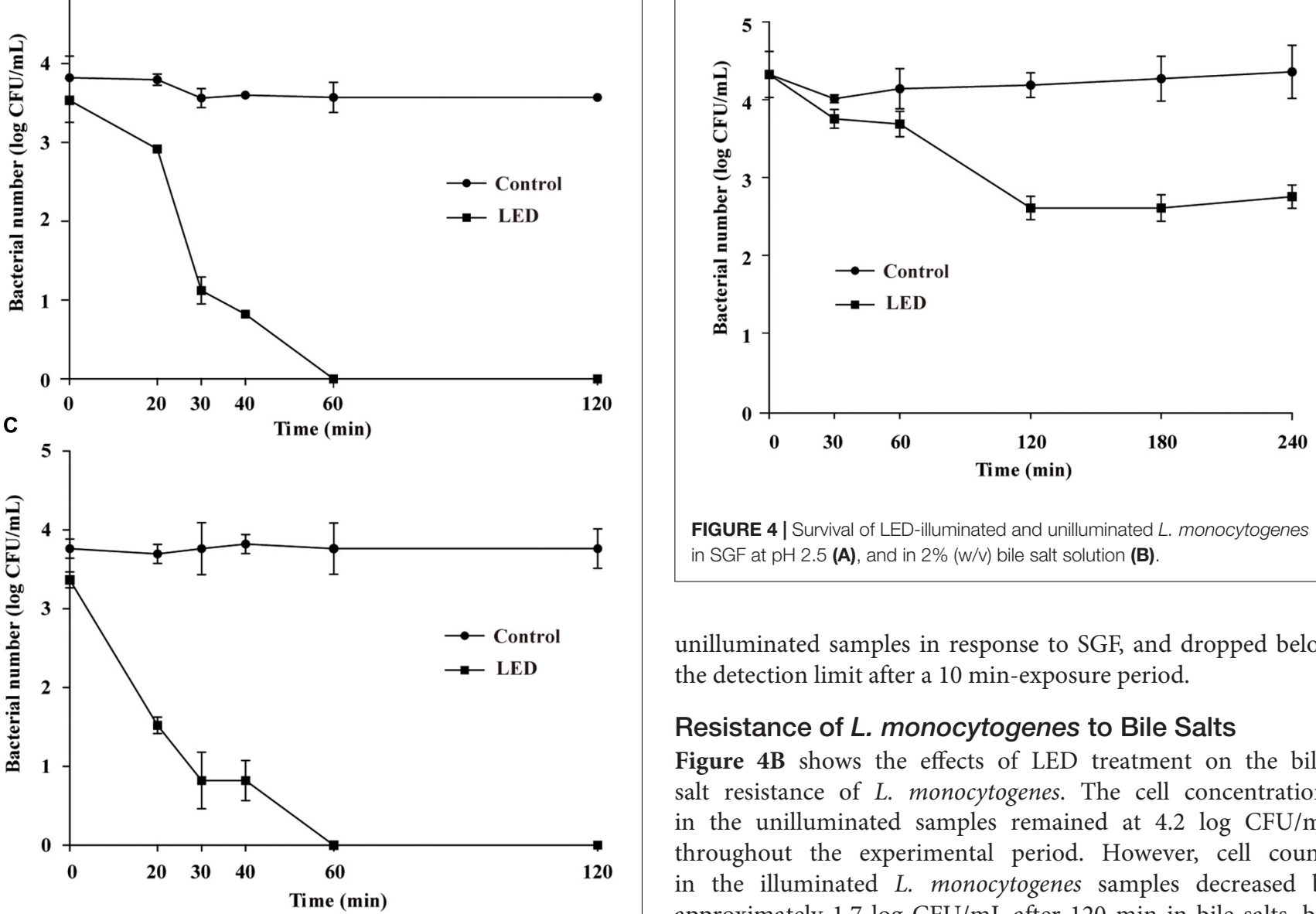

FIGURE 3 | Survival of LED-illuminated and unilluminated $L$. monocytogenes in $10 \%(\mathrm{w} / \mathrm{v}) \mathrm{NaCl}$ (A), $15 \%(\mathrm{w} / \mathrm{v}) \mathrm{NaCl}$ (B), and $20 \%(\mathrm{w} / \mathrm{v}) \mathrm{NaCl}$ (C).

5,10 , or $20 \mathrm{~min}$, the numbers of bacteria in the unilluminated populations decreased by about $0.3,0.1$, and $0.5 \log \mathrm{CFU} / \mathrm{mL}$, respectively, and dropped below the detection limit after $30 \mathrm{~min}$. Cell concentrations in the LED-illuminated L. monocytogenes samples were significantly reduced $(P<0.01)$ compared with the

FIGURE 4 | Survival of LED-illuminated and unilluminated L. monocytogenes in SGF at pH 2.5 (A), and in 2\% (w/v) bile salt solution (B).

unilluminated samples in response to SGF, and dropped below the detection limit after a 10 min-exposure period.

Resistance of $L$. monocytogenes to Bile Salts

Figure 4B shows the effects of LED treatment on the bilesalt resistance of $L$. monocytogenes. The cell concentrations in the unilluminated samples remained at $4.2 \log \mathrm{CFU} / \mathrm{mL}$ throughout the experimental period. However, cell counts in the illuminated L. monocytogenes samples decreased by approximately $1.7 \log \mathrm{CFU} / \mathrm{mL}$ after $120 \mathrm{~min}$ in bile salts, but remained unchanged from $120-240 \mathrm{~min}$.

\section{Effects of 405-nm LED Treatment on the Integrity of $L$. monocytogenes Cell Membranes}

The effects of 405-nm LED treatment on cell membrane integrity in L. monocytogenes is shown in Figure 5. Unilluminated L. monocytogenes cells showed green fluorescence at 90 and $150 \mathrm{~min}$ post-inoculation, indicating intact cells. However, 


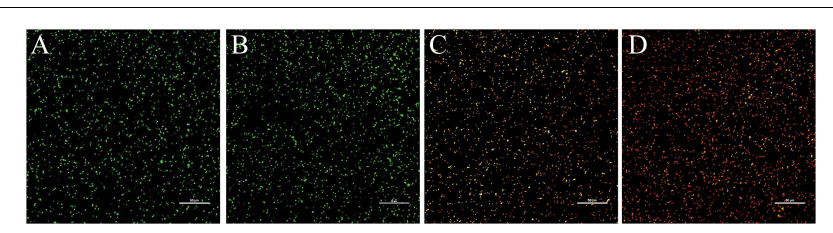

FIGURE 5 | Confocal laser scanning microscope images of L. monocytogenes. Untreated bacterial cells incubated for 90 min (A) or $150 \mathrm{~min}$ (B), and bacterial cells treated with LED illumination for $90 \mathrm{~min}$ (C) or 150 min (D) were visualized under the confocal laser scanning microscope.

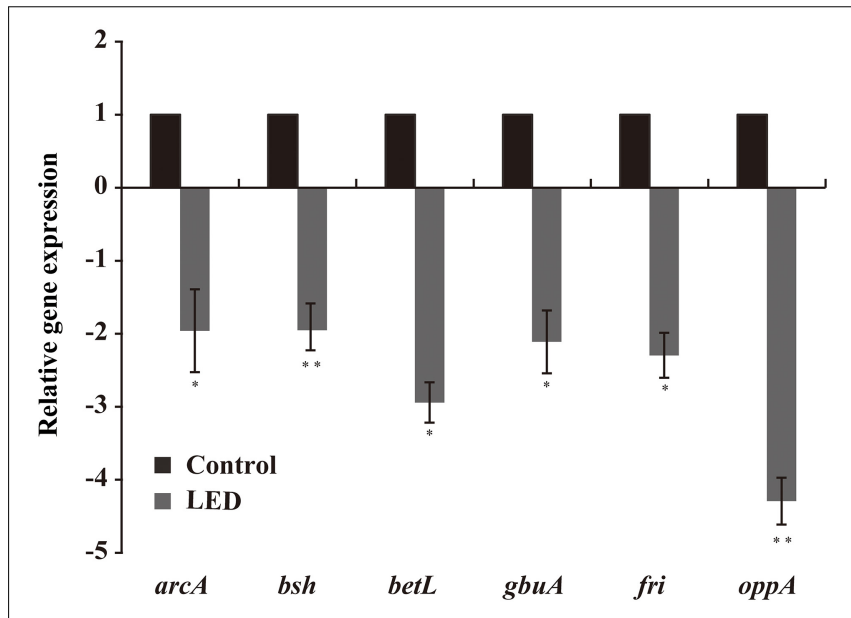

FIGURE 6 | Effects of LED treatment on the transcription of genes associated with the resistance of $L$. monocytogenes to environmental stresses. ${ }^{*} P<0.05$ and ${ }^{* *} P<0.01$ versus the control.

bacteria treated with LED illumination for 90 min displayed yellow and red fluorescence, indicating that the cell membrane had been disrupted. L. monocytogenes cells illuminated with the 405-nm LED for 150 min showed almost no green fluorescence, with an abundance of red fluorescence in the field of view. This result indicated that $405-\mathrm{nm}$ LED treatment impacted the cell membrane integrity of L. monocytogenes, and that the degree of damage increased with the period of illumination.

\section{Effects of 405-nm LED Treatment on Gene Transcription in L. monocytogenes}

As shown in Figure 6, LED treatment had a significant effect on the transcription of environmental-stress-related genes in L. monocytogenes. Transcription of betL and $g b u A$, which are associated with osmotic stress, was downregulated following LED illumination, as was that of oppA and fri (critical for cold resistance), to various degrees. Other downregulated genes included $b s h$ (critical for bile-salt resistance) and $\operatorname{arcA}$ (critical for acid resistance).

\section{DISCUSSION}

Listeria monocytogenes persists under a wide range of stress conditions (NicAogáin and O’Byrne, 2016). Food-related stress conditions encountered by L. monocytogenes along the food chain arise from various methods of preservation, and include oxidative stress generated by disinfectants, UV stress during sterilization, cold stress caused by refrigeration, and osmotic stress caused by increased salt concentrations (Bucur et al., 2018). Then, when $L$. monocytogenes enters the host's gastrointestinal tract, it encounters the acidic environment of the stomach and bile salts in the intestine, before ultimately invading host cells and triggering serious disease (Gahan and Hill, 2014). Therefore, reducing the resistance of $L$. monocytogenes to stress conditions is crucial for preventing contamination and controlling its growth along the entire food chain, from production to consumption. A previous study demonstrated that $L$. monocytogenes was reduced by $5 \mathrm{log} \mathrm{CFU} / \mathrm{mL}$ when irradiated with $108 \mathrm{~J} / \mathrm{cm}^{2}$ of illumination using a 405-nm LED (Murdoch et al., 2012), while we confirmed that the concentration of $L$. monocytogenes cells was reduced by $2.9 \log \mathrm{CFU} / \mathrm{mL}$ following exposure to $170 \mathrm{~J} / \mathrm{cm}^{2}$ of illumination using a 405-nm LED. In the present study, we investigated the ability of $405-\mathrm{nm}$ LED treatment to reduce the resistance of $L$. monocytogenes to food-related stress conditions.

Chemical oxidizing reagents, such as detergents and disinfectants, are often used to clean raw food materials and industrial equipment to prevent and control foodborne pathogens (Abeysundara et al., 2016). L. monocytogenes can survive for more than $15 \mathrm{~min}$ after exposure to the oxidative agent cumene hydroperoxide at a concentration of $13.8 \mathrm{mM}$ (Ferreira et al., 2001). In the present study, $0.04 \% \mathrm{H}_{2} \mathrm{O}_{2}$ was used to simulate an oxidative environment, with results showing that the resistance of $L$. monocytogenes to oxidative stress was significantly reduced by 405-nm LED illumination. Los and Murata (1997) reported that the resistance of $L$. monocytogenes to $0.1 \% \mathrm{H}_{2} \mathrm{O}_{2}$ was significantly enhanced after preincubation at acidic $\mathrm{pH}$ levels or pretreatment with weak organic acids. After exploring the mechanisms involved, the researchers found that the expression of sigma factor $\sigma^{S}$ (KatF) was increased and that synthesis of catalases HPI (encoded by katG) and HPII (encoded by katE) was induced. In the current study, we observed that the transcription of fri was reduced by LED illumination. fri contributes to L. monocytogenes survival in oxidative and low-iron environments because it encodes ferritin, which detoxifies oxidative agents (Olsen et al., 2005). Therefore, the reduction in the oxidative resistance of $L$. monocytogenes induced by $405-\mathrm{nm}$ LED treatment may be attributable to its effect on the abundance of ferritin.

Ultraviolet irradiation is another method used to control L. monocytogenes and other foodborne pathogens during food decontamination (Gómez-López et al., 2007). However, L. monocytogenes can persist under UV irradiation and is more resistant than Salmonella or E. coli O157:H7 when suspended in PBS or clear apple juice (Gabriel and Nakano, 2009). This difference in resistance may be related to differences in the DNA repair mechanisms used by these bacteria to combat DNA damage caused by UV light, such as photoreactivation by the enzyme photolyase and nucleotide excision repair (Sinha and Häder, 2002). We demonstrated that the number of LEDilluminated bacteria dropped below the limit of detection after UV illumination for $20 \mathrm{~s}$, confirming that 405-nm LED treatment 
significantly reduces the survival of $L$. monocytogenes following UV irradiation. A similar study showed that UV radiation is more lethal to Salmonella when combined with heat treatment, and suggested that this is related to a reduction in cell repair or to additional lethal damage caused by the interaction of the byproducts induced by the two agents (Gayán et al., 2012). However, Gayán et al. (2015) recently reported that previous exposure to sublethal doses of heat $\left(48^{\circ} \mathrm{C}, 1 \mathrm{~h}, \mathrm{pH} 7.0\right)$, acidity ( $\left.\mathrm{pH} 4.5,1 \mathrm{~h}\right)$, or alkalinity (pH 9.0, $1 \mathrm{~h}$ ) did not significantly affect the resistance of L. monocytogenes to UV.

Preservation under refrigeration is a common method of food storage. However, L. monocytogenes can proliferate to an effective concentration at $4^{\circ} \mathrm{C}$ (Tasara and Stephan, 2006). In the present study, LED illumination effectively reduced the cold resistance of L. monocytogenes to less than $24 \mathrm{~h}$. Marcos et al. (2008) reported that the cold resistance of L. monocytogenes can be reduced by high-pressure processing (400 MPa, $10 \mathrm{~min}$ ), and showed that treated bacteria do not regenerate to viable cells during longterm refrigeration. The cold resistance of $L$. monocytogenes is related to the oligopeptide permease ( $o p p)$ operon (Borezee et al., 2000). The oppA gene product plays a major role in the uptake of oligopeptides and is necessary for the growth of the bacterium at low temperatures (Cabrita et al., 2015). oppA transcription was downregulated by 405-nm LED treatment in the present study, indicating that LED treatment reduces the cold resistance of $L$. monocytogenes by affecting the expression of the opp operon.

The ability of L. monocytogenes to survive or proliferate under osmotic pressure is key to its survival and growth during food production (Bucur et al., 2018). Al-Nabulsi et al. (2015) demonstrated that L. monocytogenes can persist in highly osmotic environments $(10-20 \%(\mathrm{w} / \mathrm{v}) \mathrm{NaCl})$ because it accumulates osmolytes to reduce the osmotic pressure caused by water loss. Our results showed that 405-nm LED treatment reduced the resistance of $L$. monocytogenes to the osmotic pressure exerted by 10,15 , and $20 \%(\mathrm{w} / \mathrm{v}) \mathrm{NaCl}$ solutions. A previous study reported that compared with control samples, the bacterial counts of trans-cinnamaldehydepretreated Cronobacter sakazakii cultures decreased by more than 100,000 -fold after treatment with $75 \%$ (w/v) sorbitol for $36 \mathrm{~h}$. The researchers attributed this to the downregulation of the outer membrane proteins (OmpC, OmpR, and OsmY) involved in the transport of osmoprotectants across the bacterial cytoplasmic membrane (Amalaradjou and Venkitanarayanan, 2011). Wemekamp-Kamphuis et al. (2002) reported that the growth and survival of L. monocytogenes at high osmotic pressures are mainly attributable to the accumulation of glycine betaine and carnitine with $g b u$ and betL encoding the main glycine betaine transporters of L. monocytogenes. We demonstrated that LED treatment significantly reduced the transcription of $g b u A$ and betL potentially explaining why L. monocytogenes illuminated using 405-nm LED showed lower resistant to osmotic stress than unilluminated cells.

Prior to invading host cells, L. monocytogenes is faced with the hostile environment of the gastrointestinal tract, which is characterized by a low $\mathrm{pH}$ and is recognized as the first line of defense against foodborne pathogens (Cotter et al., 2001). Various mechanisms allow L. monocytogenes to survive and even replicate under acidic conditions, including glutamic acid decarboxylase, F0F1-ATPase, and arginine (Bucur et al., 2018). In this study, the exposure of L. monocytogenes to LED illumination reduced its survival in SGF ( $\mathrm{pH}$ 2.5). Similarly, the survival of trans-cinnamaldehyde-pretreated C. sakazakii cells was reduced in acidified TSB or infant formula milk ( $\mathrm{pH}$ 3.3), with a $>10$-fold difference in bacterial counts following exposure to trans-cinnamaldehyde for $60 \mathrm{~min}$ (Amalaradjou and Venkitanarayanan, 2011). Li et al. (2013) showed that heat shock at $47^{\circ} \mathrm{C}$ for 15 min enhanced the acid resistance of $C$. sakazakii by inducing the expression of stress-related proteins. The acid-stress-related gene $\operatorname{arcA}$ was downregulated by $405-n m$ LED illumination in the present study. ArcA activates and promotes the arginine deiminase pathway, which imports arginine molecules from the extracellular environment and protonates them to ammonium $\left(\mathrm{NH}_{4}\right)$ to increase the cellular pH (Cotter and Hill, 2003; Cheng et al., 2013). Therefore, the reduced acid resistance of $L$. monocytogenes may be attributable to the effect of 405-nm LED treatment on the arginine deiminase pathway.

Bile in the intestines disorganizes the structure of the bacterial membrane and triggers DNA damage, making it harder for L. monocytogenes to survive in and colonize the gastrointestinal tract (Hsiao et al., 2010). However, L. monocytogenes can replicate in the lumen of the gall bladder, where bile salt concentrations can reach up to $15 \%$ (Dowd et al., 2011). The human intestine contains a bile salt concentration gradient ranging between 2 and $0.05 \%$ under normal physiological conditions (Ruiz et al., 2013). Therefore, we tested the effect of LED illumination on the resistance of L. monocytogenes to a $2 \%$ bile salt solution. The number of viable LED-illuminated cells decreased faster than that of unilluminated cells at a bile salt concentration of $2 \%$ under normal physiological conditions. Similarly, Wright et al. (2016) showed that a moderate adjustment of the oxygen concentration reduced the bile-salt resistance of $L$. monocytogenes by affecting the proteomes of strains F2365, EGD-e, 10403S, and HCC23. However, Hsiao et al. (2010) reported that heat shock at $47^{\circ} \mathrm{C}$ for $15 \mathrm{~min}$ did not affect the resistance of C. sakazakii to a bile salt solution. bsh encodes bile brine hydrolase, and its deletion reduces the resistance of $L$. monocytogenes to bile salts (Dussurget et al., 2010). In current study, we showed that the transcription of bsh was downregulated by LED illumination. Therefore, we postulate that LED treatment reduces the bile-salt resistance of $L$. monocytogenes by affecting the abundance of bile brine hydrolase.

Many foodborne pathogens can survive under unfavorable conditions because they are protected by cell membranes (Beales, 2004). The main mechanism by which LED treatment inactivates microbes involves its stimulation of bacteria to produce ROS, which damage both cell membranes and proteins (Maclean et al., 2009). Therefore, we investigated changes in the integrity of the bacterial cell membrane following LED illumination. We observed that 405-nm LED illumination disrupted cell membrane integrity and reduced the resistance of L. monocytogenes to environmental stresses. Similar to our results, Kim et al. (2019) reported that cell membrane 
damage was significantly greater in E. coli $\mathrm{O} 157: \mathrm{H} 7$ at a low growth temperature, observing decreases in the resistance of the pathogen to ohmic heating as the growth temperature decreased from 37 to $15^{\circ} \mathrm{C}$. The cell membrane enhances the survival of bacteria under adverse conditions by altering its fluidity (Beales, 2004). Proteins in the cell membrane also play significant roles in the resistance of bacteria to environmental stresses. For example, outer membrane proteins (OmpC, OmpR, and OsmY) are involved in the transport of osmotic protectants in the cell membrane of Enterobacter sakazakii (Riedel and Lehner, 2010). Sudden changes in environmental conditions such as heat shock, osmotic stress, and freezing can cause changes in the cell membrane structure, including membrane damage (Los and Murata, 2004). Therefore, we assume that the destruction of the cell membrane integrity influences the resistance of $L$. monocytogenes to environmental stresses.

\section{CONCLUSION}

The results of the present study demonstrate that 405-nm LED illumination reduces the resistance of L. monocytogenes to several environmental stresses. The numbers of LEDilluminated bacteria decreased significantly compared with the control when exposed to oxidative stress $\left(0.04 \% \mathrm{H}_{2} \mathrm{O}_{2}\right)$, UV irradiation $(253.7 \mathrm{~nm})$, low temperature $\left(4^{\circ} \mathrm{C}\right)$, osmotic pressure $(10,15$, or $20 \% \mathrm{NaCl})$, SGF ( $\mathrm{pH} 2.5)$, and bile salts (2\%). CLSM and RT-qPCR analyses showed that LED illumination reduced the integrity of the bacterial cell membrane and downregulated the expression of several genes associated with environmental stress resistance. Our findings shed new light on the use of LED illumination as a promising, safe treatment for effectively controlling L. monocytogenes in the food production industry. However, the ability of 405-nm LED treatment to reduce the resistance of other L. monocytogenes strains to environmental stresses, along with the effects of the treatment on the in vivo and in vitro pathogenicity of L. monocytogenes must be further explored to evaluate the practical effects and feasibility of using 405nm LED to control L. monocytogenes and reduce the risk of human infection.

\section{REFERENCES}

Abeysundara, P. D. A., Nannapaneni, R., Soni, K. A., Sharma, C. S., and Mahmoud, B. (2016). Induction and stability of oxidative stress adaptation in Listeria monocytogenes EGD (Bug600) and F1057 in sublethal concentrations of $\mathrm{H} 2 \mathrm{O} 2$ and NaOH. Int. J. Food Microbiol. 238, 288-294. doi: 10.1016/j.ijfoodmicro. 2016.09.027

Allerberger, F., and Wagner, M. (2010). Listeriosis: a resurgent foodborne infection. Clin. Microbiol. Infect. 16, 16-23. doi: 10.1111/j.1469-0691.2009.03109.x

Al-Nabulsi, A. A., Osaili, T. M., Shaker, R. R., Olaimat, A. N., Jaradat, Z. W., Elabedeen, N. A. Z., et al. (2015). Effects of osmotic pressure, acid, or cold stresses on antibiotic susceptibility of Listeria monocytogenes. Food Microbiol. 46, 154-160. doi: 10.1016/j.fm.2014.07.015

\section{DATA AVAILABILITY}

The raw data supporting the conclusions of this manuscript will be made available by the authors, without undue reservation, to any qualified researcher.

\section{AUTHOR CONTRIBUTIONS}

SK, YM, and CS conceived and designed the experiments. DG, $\mathrm{XC}$, and JT performed the experiments. SK and YM analyzed the data. YX, SL, and XX contributed to reagents, materials, and analysis tools. SK, YM, XC, and JT wrote the manuscript.

\section{FUNDING}

This work was supported by the National Natural Science Foundation of China (31801659), the class General Financial Grant from the Shaanxi Postdoctoral Science Foundation (2018BSHEDZZ150), the Shaanxi Key Research and Development Program (2019NY-118), and the Undergraduate Innovation and Entrepreneurship Training Program (2201810712310).

\section{ACKNOWLEDGMENTS}

We thank Dr. Baowei Yang and Dr. Guoyun Zhang in Northwest A\&F University for technical assistance. We also thank Tamsin Sheen, Ph.D., from Liwen Bianji, Edanz Editing China, for editing the English text of a draft of this manuscript.

\section{SUPPLEMENTARY MATERIAL}

The Supplementary Material for this article can be found online at: https://www.frontiersin.org/articles/10.3389/fmicb. 2019.01907/full\#supplementary-material

FIGURE S1 | Temperature profile of $L$. monocytogenes suspension during 405-nm LED illumination within acrylonitrile butadiene styrene housing at $4^{\circ} \mathrm{C}$ at a distance of $4.5 \mathrm{~cm}$ from the light source.

Amalaradjou, M. A., and Venkitanarayanan, K. (2011). Effect of transcinnamaldehyde on reducing resistance to environmental stresses in Cronobacter sakazakii. Foodborne Pathog. Dis. 8, 403-409. doi: 10.1111/j.1469-0691.2009.03109.x

Bayles, D. O., Annous, B. A., and Wilkinson, B. J. (1996). Cold stress proteins induced in Listeria monocytogenes in response to temperature down shock and growth at low temperatures. Appl. Environ. Microbiol. 62, 1116-1119. doi: 10.1089/oli.1.1996.6.69

Beales, N. (2004). Adaptation of microorganisms to cold temperatures, weak acid preservatives, low pH, and osmotic stress: a review. Compr. Rev. Food Sci. Food Saf. 3, 1-20. doi: 10.1111/j.1541-4337.2004.tb00057.x

Besse, N. G., Brissonnet, F. D., Lafarge, V., and Leclerc, V. (2010). Effect of various environmental parameters on the recovery of sublethally salt-damaged and acid-damaged Listeria monocytogenes. J. Appl. Microbiol. 89, 944-950. doi: 10.1046/j.1365-2672.2000.01195.x 
Boelaert, F., Amore, G., Vander Stede, Y., Nagy, K., Rizzi, V., Mirena, I., et al. (2016). The european union summary report on trends and sources of zoonoses, zoonotic agents and food-borne outbreaks in 2016. EFSA J. 14:5077. doi: 10. 2903/j.efsa.2017.5077

Borezee, E., Pellegrini, E., and Berche, P. (2000). OppA of Listeria monocytogenes, an oligopeptide-binding protein required for bacterial growth at low temperature and involved in intracellular survival. Infect. Immun. 68, 7069-7077. doi: 10.1128/IAI.68.12.7069-7077.2000

Bredèche, M. F., Ehrlich, S. D., and Michel, B. (2001). Viability of rep recA mutants depends on their capacity to cope with spontaneous oxidative damage and on the DnaK chaperone protein. J. Bacteriol. 183, 2165-2171. doi: 10.1128/JB.183. 7.2165-2171.2001

Bucur, F. I., Gurgu, L., Crauwels, P., Riedel, C. U., and Nicolau, A. (2018). Resistance of Listeria monocytogenes to stress conditions encountered in food and food processing environments. Front. Microbiol. 9:2700. doi: 10.3389/ fmicb.2018.02700

Cabrita, P., Trigo, M. J., Ferreira, R. B., and Brito, L. (2015). Differences in the expression of cold stress-related genes and in the swarming motility among persistent and sporadic strains of Listeria monocytogenes. Foodborne Pathog. Dis. 12, 576-584. doi: 10.1089/fpd.2014.1918

Cheng, C., Chen, J., Shan, Y., Fang, C., Liu, Y., Xia, Y., et al. (2013). Listeria monocytogenes ArcA contributes to acid resistance. J. Med. Microbiol. 62, 813-821. doi: 10.1099/jmm.0.055145-0

Chorianopoulos, N., Giaouris, E., Grigoraki, I., Skandamis, P., and Nychas, G. J. (2011). Effect of acid tolerance response (ATR) on attachment of Listeria monocytogenes Scott A to stainless steel under extended exposure to acid or/and salt stress and resistance of sessile cells to subsequent strong acid challenge. Int. J. Food Microbiol. 145, 400-406. doi: 10.1016/j.ijfoodmicro.2011.01.001

Cotter, P., Gahan, C., and Hill, C. (2001). A glutamate decarboxylase system protects Listeria monocytogenes in gastric fluid. Mol. Microbiol. 40, 465-475. doi: 10.1046/j.1365-2958.2001.02398.x

Cotter, P., and Hill, C. (2003). Surviving the acid test: responses of gram-positive bacteria to low pH. Microbiol. Mol. Biol. Rev. 67, 429-453. doi: 10.1128/MMBR. 67.3.429-453.2003

Dai, T., Fuchs, B. B., Coleman, J. J., Prates, R. A., Astrakas, C., St. Denis, T. G., et al. (2012). Concepts and principles of photodynamic therapy as an alternative antifungal discovery platform. Front. Microbiol. 3:120. doi: 10.3389/fmicb.2012. 00120

Dowd, G. C., Joyce, S. A., Hill, C., and Gahan, C. G. (2011). Investigation of the mechanisms by which Listeria monocytogenes grows in porcine gallbladder bile. Infect. Immun. 79, 369-379.

Dussurget, O., Cabanes, D., Dehoux, P., Lecuit, M., Buchrieser, C., Glaser, P., et al. (2010). Listeria monocytogenes bile salt hydrolase is a PrfA-regulated virulence factor involved in the intestinal and hepatic phases of listeriosis. Mol. Microbiol. 45, 1095-1106. doi: 10.1046/j.1365-2958.2002.03080.x

Endarko, E., Maclean, M., Timoshkin, I. V., Macgregor, S. J., and Anderson, J. G. (2012). High-intensity $405 \mathrm{~nm}$ light inactivation of Listeria monocytogenes. Photochem. Photobiol. 88, 1280-1286. doi: 10.1111/j.1751-1097.2012.01173.x

Farber, J. M., Coates, F., and Daley, E. (2010). Minimum water activity requirements for the growth of Listeria monocytogenes. Lett. Appl. Microbiol. 15, 103-105. doi: 10.1111/j.1472-765X.1992.tb00737.x

Feng, Y., Qiang, Z., Li, W., and Feng, F. (2010). "Listeria monocytogenes Sigma B contributes to the tolerance of bile stress in the gastrointestinal tract," in Proceedings of the International Conference on Bioinformatics and Biomedical Engineering, (Chengdu: IEEE), doi: 10.1109/ICBBE.2010.5517287

Ferreira, A., O’Byrne, C. P., and Boor, K. J. (2001). Role of $\sigma^{\sim}$ B in heat, ethanol, acid, and oxidative stress resistance and during carbon starvation in Listeria monocytogenes. Appl. Environ. Microbiol. 67, 4454-4457. doi: 10.1128/AEM.67. 10.4454-4457.2001

Fiorini, F., Stefanini, S., Valenti, P., Chiancone, E., and De, B. D. (2008). Transcription of the Listeria monocytogenes fri gene is growth-phase dependent and is repressed directly by the ferric uptake regulator. Gene 410, 113-121. doi: 10.1016/j.gene.2007.12.007

Fisher, C. W., Lee, D., Dodge, B. A., Hamman, K. M., Robbins, J. B., and Martin, S. E. (2000). Influence of catalase and superoxide dismutase on ozone inactivation of Listeria monocytogenes. Appl. Environ. Microbiol. 66, 1405-1409. doi: 10.1128/AEM.66.4.1405-1409.2000
Gabriel, A. A., and Nakano, H. (2009). Inactivation of Salmonella, E. coli and Listeria monocytogenes in phosphate-buffered saline and apple juice by ultraviolet and heat treatments. Food Control 20, 443-446. doi: 10.1016/j. foodcont.2008.08.008

Gahan, C. G., and Hill, C. (2014). Listeria monocytogenes: survival and adaptation in the gastrointestinal tract. Front. Cell Infect. Microbiol. 4:9. doi: 10.3389/fcimb. 2014.00009

Gardan, R., Duche, O., and Leroy-Setrin, S. J. (2003). Role of ctc from Listetia monocytogenes in osmotolerance. Appl. Environ. Microbiol. 69, 154-161. doi: 10.1128/AEM.69.1.154-161.2003

Garner, D., and Kathariou, S. (2016). Fresh produce-associated listeriosis outbreaks, sources of concern, teachable moments, and insights. J. Food Prot. 79, 337-344. doi: 10.4315/0362-028X.JFP-15-387

Gayán, E., Serrano, M. J., Pagán, R., Álvarez, I., and Condón, S. (2015). Environmental and biological factors influencing the UV-C resistance of Listeria monocytogenes. Food Microbiol. 46, 246-253. doi: 10.1016/j.fm.2014. 08.011

Gayán, E., Serrano, M. J., Raso, J., Álvarez, I., and Condon, S. (2012). Inactivation of Salmonella enterica by UV-C light alone and in combination with mild temperatures. Appl. Environ. Microbiol. 78, 8353-8361. doi: 10.1128/AEM. 02010-2012

Ghate, V. S., Ng, K. S., Zhou, W., Yang, H., Khoo, G. H., Yoon, W. B., et al. (2013). Antibacterial effect of light emitting diodes of visible wavelengths on selected foodborne pathogens at different illumination temperatures. Int. J. Food Microbiol. 166, 399-406. doi: 10.1016/j.ijfoodmicro.2013.07.018

Gómez-López, V. M., Ragaert, P., Debevere, J., and Devlieghere, F. (2007). Pulsed light for food decontamination: a review. Can. J. Microbiol. 18, 464-473. doi: 10.1139/W07-042

Hsiao, W. L., Ho, W. L., and Chou, C. C. (2010). Sub-lethal heat treatment affects the tolerance of Cronobacter sakazakii BCRC 13988 to various organic acids, simulated gastric juice and bile solution. Int. J. Food Microbiol. 144, 280-284. doi: 10.1016/j.ijfoodmicro.2010.10.006

Kim, M. J., Mikš-Krajnik, M., Kumar, A., Ghate, V., and Yuk, H. G. (2015). Antibacterial effect and mechanism of high-intensity $405 \pm 5 \mathrm{~nm}$ light emitting diode on Bacillus cereus, Listeria monocytogenes, and Staphylococcus aureus under refrigerated condition. J. Photochem. Photobiol. B 153, 33-39. doi: 10. 1016/j.jphotobiol.2015.08.032

Kim, M. J., Tang, C. H., Bang, W. S., and Yuk, H. G. (2016). Antibacterial effect of $405 \pm 5 \mathrm{~nm}$ light emitting diode illumination against Escherichia coli O157:H7, Listeria monocytogenes, and Salmonella on the surface of fresh-cut mango and its influence on fruit quality. Int. J. Food Microbiol. 244, 82-89. doi: 10.1016/j. ijfoodmicro.2016.12.023

Kim, S. S., Lee, J. I., and Kang, D. H. (2019). Resistance of Escherichia coli O157:H7 ATCC 35150 to ohmic heating as influenced by growth temperature and sodium chloride concentration in salsa. Food Control 103, 119-125. doi: 10.1016/j. foodcont.2019.03.037

Lecuit, M. (2007). Human listeriosis and animal models. Microbes Infect. 9, 1216-1225. doi: 10.1016/j.micinf.2007.05.009

Li, P. T., Hsiao, W. L., Yu, R., and Chou, C. C. (2013). Effect of heat shock on the fatty acid and protein profiles of Cronobacter sakazakii BCRC 13988 as well as its growth and survival in the presence of various carbon, nitrogen sources and disinfectants. Food Microbiol. 36, 142-148. doi: 10.1016/j.fm.2013.04.018

Los, D., and Murata, N. (2004). Membrane fluidity and its roles in the perception of environmental signals. Biochim. Biophys. Acta 1666, 142-157. doi: 10.1016/j. bbamem.2004.08.002

Los, Y. Q., and Murata, A. E. (1997). Adaptation to sublethal environmental stresses protects Listeria monocytogenes against lethal preservation factors. Appl. Environ. Microbiol. 63, 1252-1255. doi: 10.1089/oli.1.1997.7.125

Luksiene, Z. (2003). Photodynamic therapy: mechanism of action and ways to improve the efficiency of treatment. Medicina 39:1137. doi: 10.3389/fmicb.2012. 00120

Maclean, M., MacGregor, S. J., Anderson, J. G., and Woolsey, G. (2009). Inactivation of bacterial pathogens following exposure to light from a 405 nanometer light-emitting diode array. Appl. Environ. Microbiol. 75, 1932-1937. doi: 10.1128/AEM.01892-1898

Marcos, B., Jofré, A., Aymerich, T., Monfort, J. M., and Garriga, M. (2008). Combined effect of natural antimicrobials and high pressure processing to 
prevent Listeria monocytogenes growth after a cold chain break during storage of cooked ham. Food Control 19, 76-81. doi: 10.1016/j.foodcont.2007.02.005

Murdoch, L. E., Maclean, M., Endarko, E., Macgregor, S. J., and Anderson, J. G. (2012). Bactericidal effects of $405 \mathrm{~nm}$ light exposure demonstrated by inactivation of Escherichia, Salmonella, Shigella, Listeria and Mycobacterium species in liquid suspensions and on exposed surfaces. ScientificWorldJournal 2012:137805. doi: 10.1100/2012/137805

Murdoch, L. E., Maclean, M., Macgregor, S. J., and Anderson, J. G. (2010). Inactivation of Campylobacter jejuni by exposure to high-intensity $405-\mathrm{nm}$ visible light. Foodborne Pathog. Dis. 7, 1211-1216. doi: 10.1089/fpd.2010.0561

NicAogáin, K., and O’Byrne, C. P. (2016). The role of stress and stress adaptations in determining the fate of the bacterial pathogen Listeria monocytogenes in the food chain. Front. Microbiol. 7:1865. doi: 10.3389/fmicb.2016.01865

Olsen, K. N., Larsen, M. H., Gahan, C. G. M., Birgitte, K., Wolf, X. A., Rosemary, R., et al. (2005). The Dps-like protein Fri of Listeria monocytogenes promotes stress tolerance and intracellular multiplication in macrophage-like cells. Microbiology 151, 925-933. doi: 10.1099/mic.0.27552-27550

Rea, R., Hill, C., and Gahan, C. G. M. (2005). Listeria monocytogenes perr mutants display a small-colony phenotype, increased sensitivity to hydrogen peroxide, and significantly reduced murine virulence. Appl. Environ. Microbiol. 71:8314. doi: $10.1128 /$ aem.71.12.8314-8322.2005

Riedel, K., and Lehner, A. (2010). Identification of proteins involved in osmotic stress response in Enterobacter sakazakii by proteomics. Proteomics 7, 1217-1231. doi: 10.1002/pmic.200600536

Rocourt, J. (2019). "Listeria monocytogenes," in Food Microbiology: Fundamentals and Frontiers, eds M. P. Doyle, L. R. Buechat, and T. J. Montville (Washingtom, DC: ASM Press), 337-352.

Ruiz, L., Margolles, A., and Sánchez, B. (2013). Bile resistance mechanisms in Lactobacillus and Bifidobacterium. Front. Microbiol. 4:396. doi: 10.3389/fmicb. 2013.00396

Scallan, E., Hoekstra, R. M., Angulo, F. J., Tauxe, R. V., Widdowson, M. A., Roy, S. L., et al. (2011). Foodborne illness acquired in the United States-major pathogens. Emerg. Infect. Dis. 17, 7-15. doi: 10.3201/eid1701.P11101

Schaffter, N., and Parriaux, A. (2002). Pathogenic-bacterial water contamination in mountainous catchments. Water Res. 36, 131-139. doi: 10.1016/s0043-1354(01) 00242-241

Shi, C., Yan, C., Sui, Y., Sun, Y., Guo, D., Chen, Y., et al. (2018). Thymoquinone inhibits virulence related traits of Cronobacter sakazakii ATCC 29544 and has anti-biofilm formation potential. Front. Microbiol. 8:2220. doi: 10.3389/fmicb. 2017.02220
Sinha, R. P., and Häder, D. P. (2002). UV-induced DNA damage and repair: a review. Photochem. Photobiol. Sci. 1, 225-236. doi: 10.1039/B201230H

Sleator, R. D., Francis, G. A., O’Beirne, D., Gahan, C. G., and Hill, C. (2003). Betaine and carnitine uptake systems in Listeria monocytogenes affect growth and survival in foods and during infection. J. Appl. Microbiol. 95, 839-846. doi: $10.1046 / j .1365-2672.2003 .02056 . x$

Tasara, T., and Stephan, R. (2006). Cold stress resistance of Listeria monocytogenes: a review of molecular adaptive mechanisms and food safety implications. J. Food Prot. 69, 1473-1484. doi: 10.4315/0362-028X-69.6. 1473

Van der Veen, S., and Abee, T. (2010). Importance of SigB for Listeria monocytogenes static and continuous-flow biofilm formation and disinfectant resistance. Appl. Environ. Microbiol. 76, 7854-7860.

Watkins, J., and Sleath, K. P. (2010). Isolation and enumeration of Listeria monocytogenes from sewage, sewage sludge and river water. J. Appl. Bacteriol. 50, 1-9. doi: 10.1111/j.1365-2672.1981.tb00865.x

Wemekamp-Kamphuis, H. H., Wouters, J. A., Sleator, R. D., Gahan, C. G., Hill, C., and Abee, T. (2002). Multiple deletions of the osmolyte transporters BetL, $\mathrm{Gbu}$, and $\mathrm{OpuC}$ of Listeria monocytogenes affect virulence and growth at high osmolarity. Appl. Environ. Microbiol. 68, 4710-4716. doi: 10.1128/AEM.68.10. 4710-4716.2002

Wright, M. L., Pendarvis, K., Nanduri, B., Edelmann, M. J., Jenkins, H. N., Reddy, J. S., et al. (2016). The effect of oxygen on bile resistance in Listeria monocytogenes. J. Proteomics Bioinform. 9, 107-119. doi: 10.4172/jpb.1000396

Yang, H. Y., Kim, S. K., Choi, S. Y., You, D. H., Lee, S. C., Bang, W. S., et al. (2015). Effect of acid, desiccation and heat stresses on the viability of Cronobacter sakazakii during rehydration of powdered infant formula and in simulated gastric fluid. Food Control 50, 336-341. doi: 10.1016/j.foodcont.2014.09.012

Conflict of Interest Statement: The authors declare that the research was conducted in the absence of any commercial or financial relationships that could be construed as a potential conflict of interest.

Copyright $\odot 2019$ Kang, Meng, Cheng, Tu, Guo, Xu, Liang, Xia and Shi. This is an open-access article distributed under the terms of the Creative Commons Attribution License (CC BY). The use, distribution or reproduction in other forums is permitted, provided the original author(s) and the copyright owner(s) are credited and that the original publication in this journal is cited, in accordance with accepted academic practice. No use, distribution or reproduction is permitted which does not comply with these terms. 